\title{
Epidermoid Cyst of the Auricle: A Common Cyst at a Rare Site
}

\section{Vinson Louis Gonzaga Fernandes*, Nina Margarida De Gouveia Pinto, Ombretta Barreto, Joevito Furtado, Siddhartha Basuroy}

Department of Otorhinolaryngology and Head \& Neck Surgery, Goa Medical College and Hospital, Bambolim, India

Email: *fernandesvinson@yahoo.com

How to cite this paper: Fernandes, V.L.G., De Gouveia Pinto, N.M., Barreto, O., Furtado, J. and Basuroy, S. (2018) Epidermoid Cyst of the Auricle: A Common Cyst at a Rare Site. International Journal of Otolaryngology and Head \& Neck Surgery, 7, 344-349.

https://doi.org/10.4236/ijohns.2018.76034

Received: October 6, 2018

Accepted: November 9, 2018

Published: November 12, 2018

Copyright $\odot 2018$ by authors and Scientific Research Publishing Inc. This work is licensed under the Creative Commons Attribution International License (CC BY 4.0).

http://creativecommons.org/licenses/by/4.0/

\begin{abstract}
Epidermoid cysts are benign, developmental, superficial cysts found commonly on the face, trunk and neck. Its presence on the ear lobe is very rare. We shall describe the occurrence of an epidermoid cyst on the auricle along with the presence of a dermoid cyst over the occipital scalp and elaborate on the patient presentation, diagnosis, management along with the post-operative follow up.
\end{abstract}

\section{Keywords}

Epidermoid Cyst, Lobule, Auricle

\section{Introduction}

Epidermoid cysts represent the most common cutaneous cysts which can occur anywhere in the body but are more commonly seen over the face, scalp, neck and trunk [1]. The auricle is one of the rare locations. Epidermoid cysts have a varying nomenclature, including follicular cysts, infundibular cysts and epidermal inclusion cysts. Epidermoid cysts result from dermal implantation of epidermal elements. They are usually benign but in very rare circumstances are associated with malignancy [2] [3] [4].

Males are predisposed in a ratio of 2:1.

Epidermoid cysts are mostly asymptomatic, but can become infected or inflamed. Certain crush injuries have been associated with terminal phalanx or subungal epidermoid cysts. Any surgical procedure (rhinoplasty, breast augmentation and liposuction) can also result in the formation of multiple epidermoid cysts [5]. Their formation is also associated with the use of auto grafts (dermal, myocutaneous) and the use of fine needle aspiration cytology. 
Certain hereditary syndromes like Pachyonychia congenital, Gardner syndrome, Basal cell nevus syndrome are associated with epidermoid cysts [3] [6] [7]. Roser first gave the term epidermoid cyst in 1859 [8].

The objective of our case report is to highlight the occurrence of a common tumor in a rare location, like the lobule of the pinna and the importance of subjecting the same to histopathological examination owing to its association with malignancy.

\section{Case Report}

A 23-year-old male presented to Goa Medical College ENT OPD with history of noticing a swelling on right ear since 4 months. Onset was insidious and gradually progressive. Initially it was the size of a peanut and over the last 2 months has increased to its present size as that of a small lime (Figure 1). It was painless. There was history of noticing another swelling on the back of the scalp as well, which had the same onset and duration (Figure 2). On examination, there was a $2 \times 2 \mathrm{cms}$ swelling on the medial aspect of the lobule of the right pinna. It was firm, mobile and non-tender on palpation.

It had a smooth and regular surface without a central punctum. Skin overlying the swelling was normal. There was no ear lobe piercing noted. Rest of the pinna, external auditory canal and tympanic membrane on the right side was within normal limits. Neck examination revealed no cervical lymphadenopathy. There was another swelling on the left occipital scalp, which was $3 \times 3 \mathrm{cms}$ in size, firm, mobile and non-tender on palpation. It also had a smooth and regular surface without a central punctum.

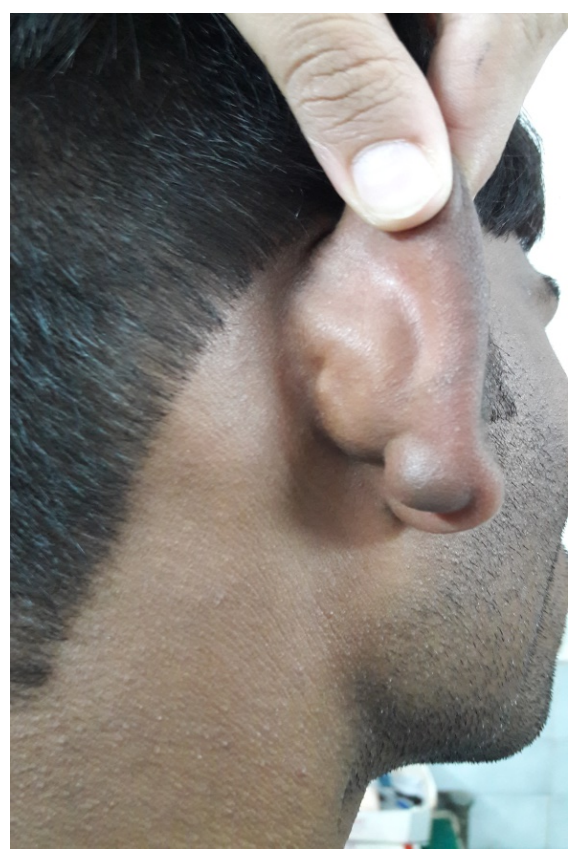

Figure 1. Clinical photograph showing the epidermoid cyst on the medial aspect of right pinna lobule. 


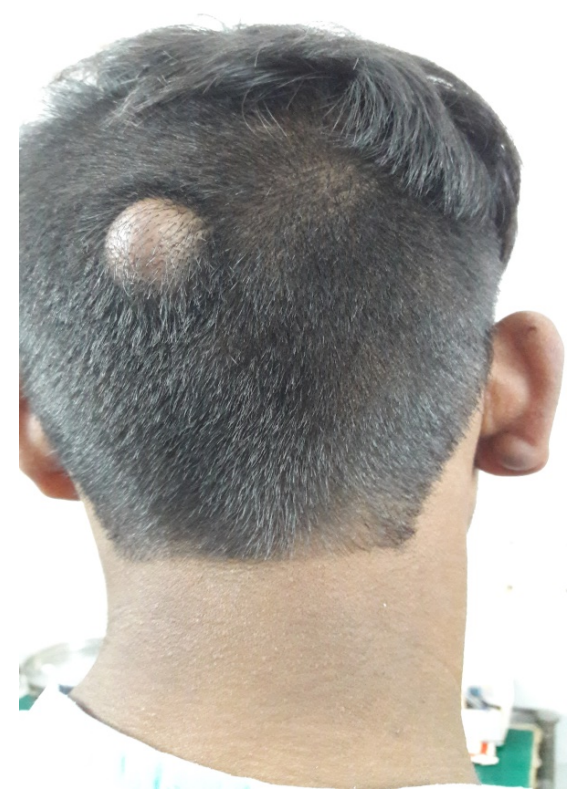

Figure 2. Clinical photograph showing the epidermoid cyst on the medial aspect of right pinna lobule along with the dermoid cyst on the left occipital scalp.

A differential diagnosis of an epidermoid cyst, dermoid cyst, benign tumor was made. All blood results were normal. Patient was counseled and explained about the need for surgery. He was then posted for excision of the right pinna lobule mass under local anesthesia (Figures 3(a)-(d)) after obtaining a well-informed written consent from the patient.

Excision of the cyst was done under local anesthesia in our minor operation theatre (Figure 4) and sent for histopathological examination.

Patient was referred to general surgery for excision of the scalp mass, which was done under local anesthesia and sent for histopathological analysis.

Patient recovered very well post operatively. Histopathological examination of the right pinna lobule mass revealed an encapsulated cyst lined by stratified squamous epithelium along with keratin material in the center, without any adnexal structures such as sweat glands, hair noted. A histopathological diagnosis of an epidermoid cyst was made (Figure 5). Histopathological examination of the occipital scalp mass revealed a dermoid cyst. He was followed up for over 6 months with no evidence of any recurrence. Overall prognosis was good. Patient gave his consent for a case report to be published.

\section{Discussion}

The occurrence of an epidermoid cyst of the auricle is a rare entity and its association with the presence of a dermoid cyst of the scalp makes it very rare case. Only a few ear lobe epidermal cysts have been reported in literature [9].

They usually occur in the $3^{\text {rd }}$ and $4^{\text {th }}$ decade of life, with males being more predisposed than females. They commonly occur at sites like face, scalp, trunk 
etc. Epidermal cysts are mostly benign asymptomatic cysts that rarely become inflamed or infected secondarily. Over a period of time, epidermal cysts can develop into malignancies like epidermal cyst carcinomas, Bowens disease, basal cell carcinoma and melanoma in situ [10]. Other rare locations of epidermal cysts include the breast, intra cranial areas, pre-sternal, pre-sacral, popliteal region and even on the feet [9] [11]. The external ear however, is one of the rarest of rare locations. Epidermal cysts of the post auricular region must be differentiated from lipomas and hemangiomas. Lipomas are benign fatty tissue containing tumors and hemangiomas which are usually present at birth are benign tumors of the vascular endothelia [12].

One of the associated problems with large epidermal cysts is their ugly, unaesthetic appearance, so many patients go under the knife for cosmetic reasons, as more often than not epidermal cysts are asymptomatic.

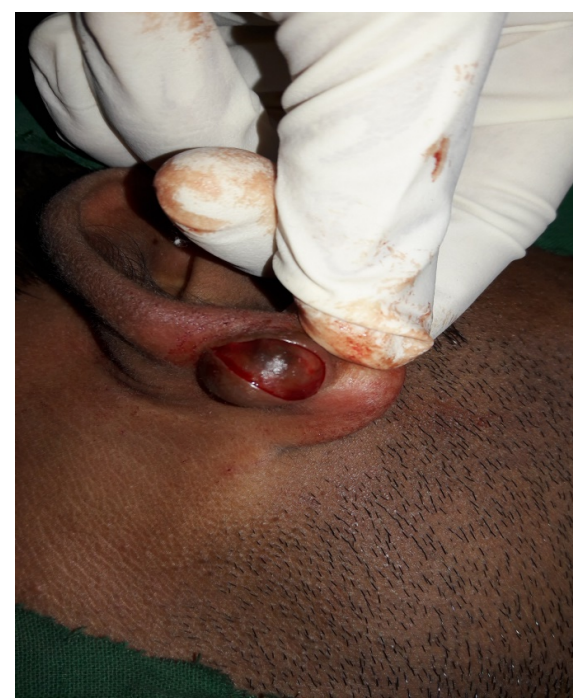

(a)

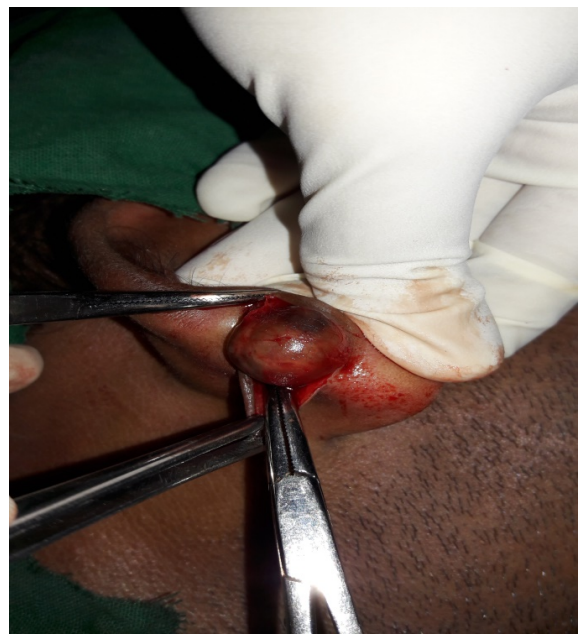

(c)

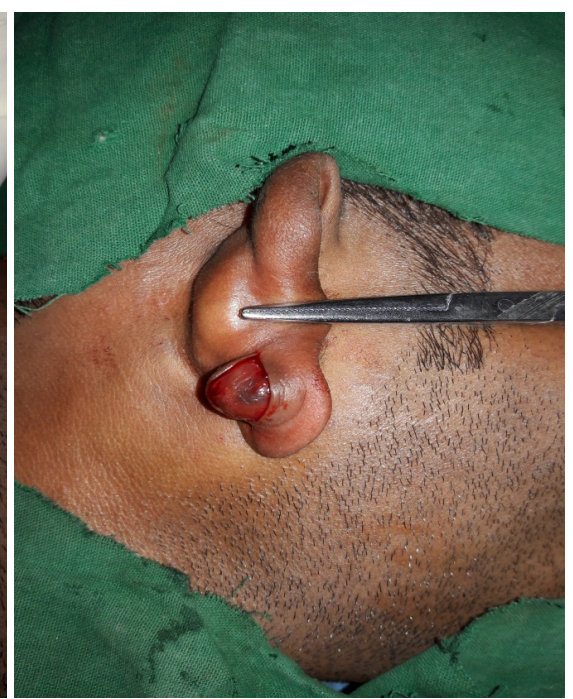

(b)

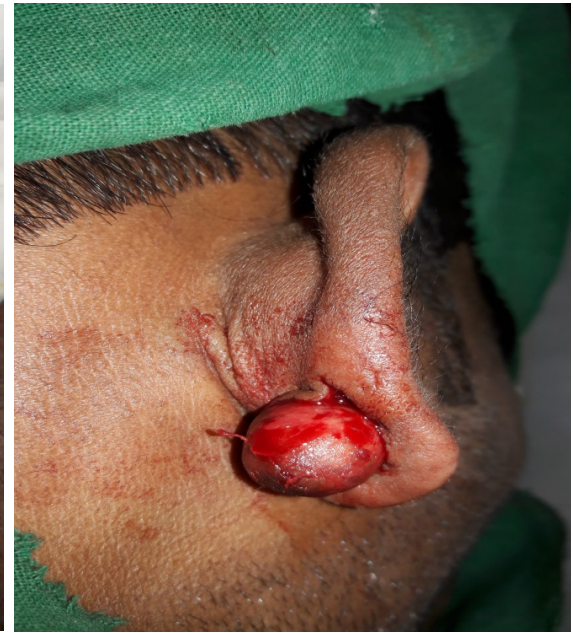

(d)

Figure 3. Intra operative photographs of the excision of the right pinna lobule cyst under local anesthesia. 


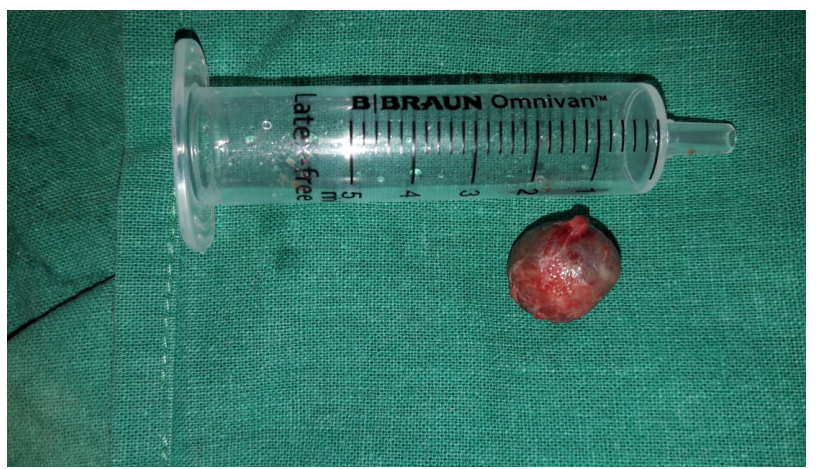

Figure 4. Post-operative photograph of the completely excised pinna lobule cyst in total.

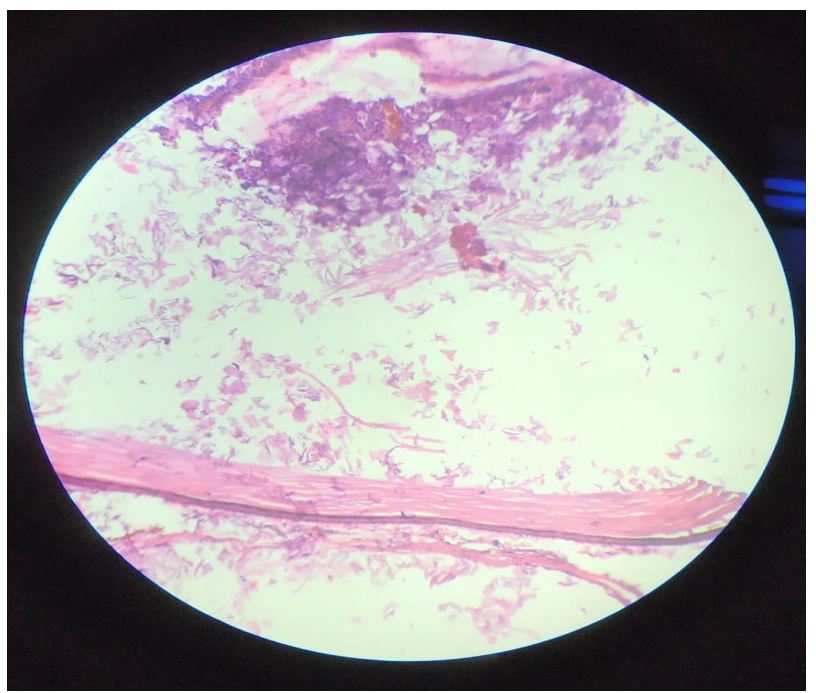

Figure 5. Photomicrograph showing an encapsulated cyst lined by stratified squamous epithelium along with keratin material in the center, suggestive of an epidermoid cyst.

\section{Conclusion}

This rare case report highlights the occurrence of an epidermal cyst of the auricle along with a dermoid cyst over the scalp. It is very important to completely excise the cyst and differentiate between benign and malignant tumors on histopathology.

\section{Conflicts of Interest}

The authors declare no conflicts of interest regarding the publication of this paper.

\section{References}

[1] Handa, U., Kumar, S. and Mohan, H. (2002) Aspiration Cytology of Epidermoid Cyst of Terminal Phalanx. Diagnostic Cytopathology, 26, 266-267. https://doi.org/10.1002/dc. 10075

[2] Aloi, F., Tomasini, C. and Pippione, M. (1993) Mycosis Fungoides and Eruptive 
Epidermoid Cysts: A Unique Response of Follicular and Eccrine Structures. Dermatology, 187, 273-277. https://doi.org/10.1159/000247263

[3] Barr, R.J., Headley, J.L., Jensen, J.L. and Howell, J.B. (1986) Cutaneous Keratocysts of Navoid Basal Cell Carcinoma Syndrome. Journal of the American Academy of Dermatology, 14, 572-576. https://doi.org/10.1016/S0190-9622(86)70071-6

[4] Bauer, B. (1979) Carcinoma Arising in a Sebaceous Cyst. Internal Medicine Journal, 156, 174-176.

[5] Bechara, F.G., Sand, M., Rotterdam, S., Altmeyer, P. and Hoffman, K. (2008) Multiple Epidermal Inclusion Cysts after Axillary Liposuction-Curettage. A Rare Complication of a Frequent Procedure. International Journal of Dermatology, 47, 1197-1198. https://doi.org/10.1111/j.1365-4632.2008.03686.x

[6] Ogata, K., Ikeda, M., Miyoshi, K., et al. (2001) Naevoid Basal Cell Carcinoma Syndrome with a Palmar Epidermoid Cyst, Milia and Maxillary Cysts. British Journal of Dermatology, 145, 508-509. https://doi.org/10.1046/j.1365-2133.2001.04389.x

[7] Rios-Buceta, L.M., Fraga-Fernandez, J. and Fernandez-Herrera, J. (1992) Human Papillomavirus in an Epidermoid Cyst of the Sole in a Non-Japanese Patient. Journal of the American Academy of Dermatology, 27, 364-366.

https://doi.org/10.1016/0190-9622(92)70201-P

[8] Shivakumar, M.S., Yogesh, T.L., Nagaraj, T. and Sinha, P. (2015) Epidermal Inclusion Cyst of Buccal Mucosa: A Rare Case Report. International Journal of Medical and Dental Case Reports, Article ID: 050115.

[9] Joaquin, P.G., Allesandra, S., Emilio, C.-S., Rioja Luiz, F. and Rosario, P. (2012) Giant Earlobe Epidermoid Cyst. Journal of Cutaneous and Aesthetic Surgery, 5, 38-39. https://doi.org/10.4103/0974-2077.94342

[10] Swygert, K.E., Parrish, C.A., Cashma, R.E., Lin, R. and Cockerell, C.J. (2007) Melanoma in Situ Involving an Epidermal Inclusion (Infundibular) Cyst. The American Journal of Dermatopathology, 29, 564-565. https://doi.org/10.1097/DAD.0b013e3181513e5c

[11] Karacal, N., Topal, U. and Kutlu, N. (2004) Popliteal Epidermoid Cyst: An Unsual Location. Plastic and Reconstructive Surgery, 114, 830-831. https://doi.org/10.1097/01.PRS.0000136543.54426.AF

[12] Dive Alka, M., Shughangi, K., Rohit, M. and Shrutal, D. (2012) Epidermoid Cyst of the Outer Ear: A Case Report and Review of literature. Indian Journal of Otology, 18, 34-37. 